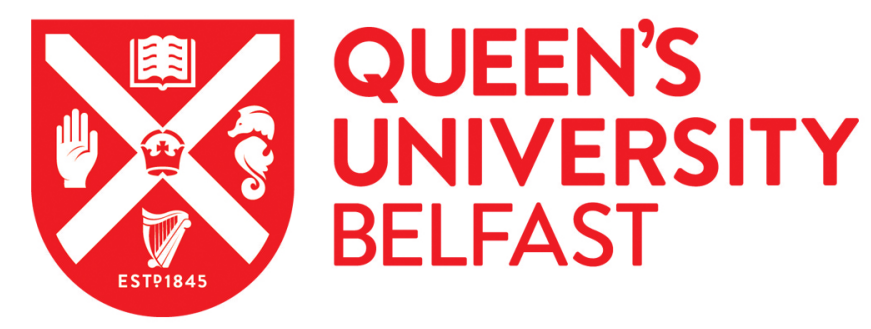

\title{
Ecological impacts of invasive alien species along temperature gradients: testing the role of environmental matching
}

lacarella, J. C., Dick, J. T. A., Alexander, M. E., \& Ricciardi, A. (2015). Ecological impacts of invasive alien species along temperature gradients: testing the role of environmental matching. Ecological Applications, 25(3), 706-716. https://doi.org/10.1890/14-0545.1

Published in:

Ecological Applications

Document Version:

Publisher's PDF, also known as Version of record

Queen's University Belfast - Research Portal:

Link to publication record in Queen's University Belfast Research Portal

\section{Publisher rights}

Copyright 2015 by the Ecological Society of America. Josephine C. lacarella, Jaimie T. A. Dick, Mhairi E. Alexander, and Anthony Ricciardi 2015. Ecological impacts of invasive alien species along temperature gradients: testing the role of environmental matching. Ecological Applications 25:706-716. http://dx.doi.org/10.1890/14-0545.1

\section{General rights}

Copyright for the publications made accessible via the Queen's University Belfast Research Portal is retained by the author(s) and / or other copyright owners and it is a condition of accessing these publications that users recognise and abide by the legal requirements associated with these rights.

Take down policy

The Research Portal is Queen's institutional repository that provides access to Queen's research output. Every effort has been made to ensure that content in the Research Portal does not infringe any person's rights, or applicable UK laws. If you discover content in the Research Portal that you believe breaches copyright or violates any law, please contact openaccess@qub.ac.uk. 


\title{
Ecological impacts of invasive alien species along temperature gradients: testing the role of environmental matching
}

\author{
Josephine C. Iacarella, ${ }^{1,2}$ Jaimie T. A. Dick, ${ }^{3}$ Mhairi E. Alexander, ${ }^{4}$ and Anthony Ricciardi ${ }^{1,2,5}$ \\ ${ }^{1}$ Group for Interuniversity Research in Limnology and Aquatic Environment, McGill University, Montreal, Quebec H3A OC4 Canada \\ ${ }^{2}$ Redpath Museum and Department of Biology, McGill University, 859 Sherbrooke Street West, Montreal, Quebec H3A OC4 Canada \\ ${ }^{3}$ Institute for Global Food Security, School of Biological Sciences, Queen's University Belfast, 97 Lisburn Road, \\ Belfast BT9 7BL Northern Ireland, United Kingdom \\ ${ }^{4}$ Centre for Invasion Biology, Department of Botany and Zoology, Stellenbosch University, Private Bag X1, \\ Matieland 7602 South Africa
}

\begin{abstract}
Invasive alien species (IAS) can cause substantive ecological impacts, and the role of temperature in mediating these impacts may become increasingly significant in a changing climate. Habitat conditions and physiological optima offer predictive information for IAS impacts in novel environments. Here, using meta-analysis and laboratory experiments, we tested the hypothesis that the impacts of IAS in the field are inversely correlated with the difference in their ambient and optimal temperatures. A meta-analysis of 29 studies of consumptive impacts of IAS in inland waters revealed that the impacts of fishes and crustaceans are higher at temperatures that more closely match their thermal growth optima. In particular, the maximum impact potential was constrained by increased differences between ambient and optimal temperatures, as indicated by the steeper slope of a quantile regression on the upper 25th percentile of impact data compared to that of a weighted linear regression on all data with measured variances. We complemented this study with an experimental analysis of the functional response (the relationship between predation rate and prey supply) of two invasive predators (freshwater mysid shrimp, Hemimysis anomala and Mysis diluviana) across relevant temperature gradients; both of these species have previously been found to exert strong community-level impacts that are corroborated by their functional responses to different prey items. The functional response experiments showed that maximum feeding rates of $H$. anomala and $M$. diluviana have distinct peaks near their respective thermal optima. Although variation in impacts may be caused by numerous abiotic or biotic habitat characteristics, both our analyses point to temperature as a key mediator of IAS impact levels in inland waters and suggest that IAS management should prioritize habitats in the invaded range that more closely match the thermal optima of targeted invaders.
\end{abstract}

Key words: environmental matching; functional response; impact; inland waters; meta-analysis; nonnative species; thermal optima.

\section{INTRODUCTION}

Spatial and temporal variation in the impact of invasive alien species (IAS) can be generated by local abiotic conditions (Ricciardi et al. 2013). In particular, shifts in temperature regimes caused by climate change are expected to alter the ecological impacts of IAS (Hellmann et al. 2008, Rahel and Olden 2008, Walther et al. 2009) by affecting their abundance, how much area they occupy, and their per capita effects (Parker et al. 1999). Per capita effects may propagate impacts through trophic and competitive interactions up to a thermal optimum, where traits such as feeding rates are maximized, and such impacts are expected to be reduced at temperatures above and below optimum (Huey and Stevenson 1979, Jobling 1981). For example, differences

Manuscript received 21 March 2014; revised 20 July 2014; accepted 27 August 2014. Corresponding Editor: O. P. Jensen.

${ }_{5}^{5}$ Corresponding author. E-mail: tony.ricciardi@mcgill.ca in thermal optima can create competitive imbalances that result in a species being a superior competitor in its optimal habitat conditions but inferior in suboptimal habitat conditions (Dunson and Travis 1991, Taniguchi et al. 1998).

The Environmental Matching Hypothesis (Ricciardi et al. 2013) predicts that the impacts of an invader, as defined by its per capita effect and abundance (Parker et al. 1999), decline as habitat conditions move further from its physiological optimum. A few studies have shown that impacts of IAS are higher in the environmental conditions for which they are adapted (e.g., oxygen concentration [MacNeil et al. 2004]; salinity [Alcaraz et al. 2008]; conductivity [Kestrup and Ricciardi 2009]). However, assessments of how climate change can affect the consumptive per capita impact of IAS are lacking in comparison to investigations of how abundance and area occupied will be affected (Parker et al. 1999, Hellmann et al. 2008). Although the establishment of IAS in novel environments has been predicted by the 
degree of match with environmental conditions in the native range (e.g., niche-based modeling; Peterson 2003, Bomford et al. 2010, Britton et al. 2010), to our knowledge no such procedure has been applied to impact; measurements of functional and physiological responses along environmental gradients could be useful predictors of the consumptive impacts of established IAS on native communities. Here, we provide the first general test of the Environmental Matching Hypothesis by conducting a meta-analysis of published data to examine the importance of temperature in determining IAS impact levels. We complement this analysis with an experimental approach that derives per capita effects over ecologically relevant temperature gradients for two IAS with documented high consumptive impacts.

Important insights into the per capita effects of an invader can be gained by measuring its functional response (FR; Dick et al. 2013, 2014), defined as the relationship between predation rate and prey supply (Holling 1959). FR analysis is a promising new method of understanding and predicting the success and impact of introduced species (Dick et al. 2014). For instance, IAS with strong impacts on native freshwater communities have been found to exhibit higher maximum feeding rates than natives (Alexander et al. 2014) and lower-impact invaders (Bollache et al. 2008). Maximum feeding rate is a physiologically-dependent parameter of FR and is generally limited by the time required for the predator to handle, consume, and digest its prey (Holling 1959, 1966). A previous meta-analysis of the temperature dependence of maximum feeding rates indicated a modal (concave down) relationship for fishes, crustaceans, insects, and mites (Englund et al. 2011). Therefore, maximum feeding rate serves as a performance metric (Huey and Stevenson 1979) that could be used to indicate temperatures and other abiotic conditions that result in the greatest per capita impact of IAS in the field.

While FR provides an efficient tool for relative predictions of per capita effect, a more complete measurement of impact would include the abundance of the IAS (Parker et al. 1999, Yokomizo et al. 2009, Thomsen et al. 2011). A meta-analysis on inland water and marine systems revealed that higher abundances of IAS lead to increased ecological impacts across taxonomic groups and feeding strategies (Thomsen et al. 2011). Two sources of variation in the abundance of populations are the numerical response, the response of consumers to resource densities through population growth and aggregation or dispersal (Holling 1966), and physiological responses, such as rates of reproduction and somatic growth, to abiotic habitat conditions (Solomon 1949, Pörtner and Knust 2007). In particular, growth rates of individuals along a temperature gradient have been found to coincide with changes in field abundances owing to warming temperatures (Pörtner and Knust 2007). Bioenergetics models have been developed for animals such as crustaceans and can be used to predict the consumptive impact of an individual if its growth is known, and vice versa (Clutter and Theilacker 1971, Lasenby and Langford 1972, Rudstam 1989, Gorokhova 1998, Chipps and Bennett 2002). However, FR and growth rate measures may provide more accessible tools for risk assessments of potential impacts of large numbers of IAS. Here, we extend the FR methodology to derive per capita effects of two invasive freshwater crustaceans, the Ponto-Caspian mysid Hemimysis anomala and the North American mysid Mysis diluviana, across relevant temperature gradients in comparison to optimal growth conditions. Individuals of $H$. anomala in North America and Ireland have been found to have higher maximum feeding rates on multiple prey types than functionally similar mysids, with results predicting field impacts (Dick et al. 2013). Introduced $M$. diluviana have caused severe declines in zooplankton, particularly cladocerans, and have negatively impacted multiple trophic levels through cascading effects on top predators by reducing basal food resources for fish (Spencer et al. 1991, Ellis et al. 2011).

We first conducted a meta-analysis on documented field experiments to assess how the consumptive impacts of IAS in inland waters change across temperature gradients in relation to their thermal growth optima. Then, we measured FRs of $H$. anomala and $M$. diluviana across their respective temperature tolerance ranges. The meta-analysis incorporates both per capita and abundance impacts of IAS, whereas the FRs provide direct measures of per capita effects. We show that by relating FRs to the thermal growth optima of IAS we can develop predictions for the temperature range that enables maximum impact potential based on per capita effect and abundance as represented by growth rates. We predicted that (1) consumptive impacts of IAS would be strongest in habitats that most closely match their thermal optima (the Environmental Matching Hypothesis; Ricciardi et al. 2013); and (2) maximum feeding rates of $H$. anomala and $M$. diluviana would be highest near reported optimal growth temperatures.

\section{Methods \\ Meta-analysis: data collection}

We used Web of Science and Google Scholar to search for published data on changes in abundance of native populations attributed to direct predation, herbivory, or filter feeding by IAS in inland waters (lakes, rivers, and estuaries). We chose to focus on inland water systems because climate change induced shifts in temperature are likely to have a larger effect on IAS in these systems; the more defined biogeographic barriers of inland water systems compared with terrestrial and marine systems reduce the potential for natural range shifts toward more optimal temperatures (Rahel and Olden 2008). Search terms included the following combinations: "invasive," "invader," or Latin/common names of species that appeared under the former search terms, combined with "impact," "effect," "enclosure," 
"mesocosm," "temperature," or "predation." Papers were first culled based on whether the study organism was an inland water invader and the study was performed in the field. To capture impacts in natural systems, we used only studies that employed field (enclosure, exclosure, and mesocosm) experiments and surveys; when raw data were not provided, we used Data Thief (Tummers 2006) to extract values from figures. Cumulative measures of an invader's impact on groups of prey (e.g., predation on total benthic invertebrates) were used preferentially as a single data point; otherwise, measurements of impacts on each individual prey item within an experimental treatment were used as individual data points (see Appendix: Table A1 for all data sources and values). When multiple densities of invaders were tested in a study, the lowest density was always selected in order to standardize comparisons between studies; for instance, for Mills and colleagues (2004), who test fish densities of 6 and 100 individuals, we selected the impact data for 6 individuals, as most other fish studies in our data set measured impacts of less than 10 individuals. Data were also included for separate habitats within the same study. In the case of repeated measures, we selected the time period that provided the most accurate measurements of temperature conditions and allowed for higher impacts to be observed, based on the following criteria in order of importance: (1) habitat temperatures were provided for the specific time period ( 1 out of 10 studies); (2) the time period corresponded with peaks in prey abundance (2 out of 10 studies); or (3) the time period represented a longer duration of impact (7 out of 10 studies). When a study contained multiple experiments, we chose the experiment that had the most detailed temperature measurements or, otherwise, the experiment that had the most natural conditions (e.g., mesocosms containing a greater number of native species). Taking data from multiple experiments within the same study would not have added value to the data set by providing different ambient temperature comparisons as experiments were generally done at similar temperatures; this would also have increased potential pseudo-replication. Water temperatures for the study system were obtained from the study itself, other studies on the same system, or online climatic databases. Diel migrators such as mysids experience a range of temperatures throughout the day (Beeton and Bowers 1982), and their overall feeding and growth rates are directly related to the amount of time they spend at each temperature (Johannsson et al. 2008); therefore, we selected temperature measurements that best corresponded with the time and site at which the impact was measured.

Data were collected from published literature on thermal optima of the IAS for which quantifiable impacts had been recorded based on the previous criteria. Optimum conditions are those that maximize performance such as reproductive effort, growth, or feeding rate (Huey and Stevenson 1979, Jobling 1981).
Optima can depend on the life-stage of the organism (Anger 1991, Epifanio et al. 1998, Rudnick et al. 2005) and the performance parameter of interest (Sankurathri and Holmes 1976, Charlebois et al. 1997). Therefore, an effort was made to use growth optima of similar life stages of IAS, as this was assumed to relate more directly to both resource consumption and abundance than does reproductive success and also maintains independence from predation/herbivory impact measurements. Locating studies that measured the growth optima of IAS along temperature gradients was a limiting requirement for the meta-analysis, so optima were included regardless of whether they were measured on populations from the native or invaded range. For each study, we calculated the difference between water temperatures corresponding with the impact measurement and the invader's documented thermal optimum. Optima can cover a range of conditions rather than peak at a single value (Huey and Stevenson 1979); therefore, study conditions falling within that range were calculated as zero difference.

\section{Meta-analysis procedures}

Mean abundances of native populations with $\left(\bar{X}_{\mathrm{I}}\right)$ and without the invader $\left(\bar{X}_{\mathrm{NI}}\right)$ were used to calculate a log response ratio (LR; Hedges et al. 1999) for comparing impact levels, where LR $=\ln \left(\bar{X}_{\mathrm{I}}\right)-\ln \left(\bar{X}_{\mathrm{NI}}\right)$. Unlike other commonly used metrics, this one does not confound differences in variance between studies with differences in the size of effect (Osenberg et al. 1997), nor does it depend on the magnitude of the average value of the response variable in a study (Englund et al. 1999). Changes in native populations were measured in numerical densities, abundances, ratios of pre- and post-experiment abundances, and percentages. Given that the LR is undefined in cases where a zero impact value is recorded, a detection limit (derived from the number of significant digits reported in the study, e.g., 0.01) was added to the numerators of all LRs within a study for which there was at least one measurement of zero native population abundance in the presence of the invader; 19 of 87 data points were treated thusly (Appendix: Table A1). Viola and colleagues (2010) corrected zero values by adding the lowest detected value of the response variable within a study to all observations within the study; our method is less biased against measures of high impact. Graphical inspection of the data showed that LRs adjusted with a detection limit were not outliers and represented only two of the highest impacts (those defining the outer envelope) along the temperature difference gradient.

We were able to fit a weighted linear regression model using 11 IAS from 19 studies that included only LRs for which we could calculate sample variances (variances were calculated with MetaWin [Rosenberg et al. 2000]; regression was fit with metafor package 1.9-2 [Viechtbauer 2010]). A fixed-effects least squares regression analysis weighted by within-study variances was used to 
assess the effect of absolute temperature difference between study conditions and thermal optima on impacts (negative LRs) of IAS (Gurevitch and Hedges 1999, Borenstein et al. 2009). We did not weight LRs by between-study variance, as estimates of between-study variance can have poor precision when the number of studies is small (Borenstein et al. 2009).

An assumption of meta-analyses is that individual effect sizes are independent (Hedges and Olkin 1985). Given that multiple LRs were calculated for some studies and species, intraclass correlation coefficients (ICC) were used to determine the magnitude of nonindependence of LRs within studies and species (ICC package 2.2.1; Wolak et al. 2012), as has been done in other meta-analytical studies (e.g., Haxton and Findley 2008). Intraclass correlation coefficients indicated lack of dependence of LRs measured within studies (ICC $=0.19$ ) and within species ( ICC $=0.02)$. Owing to independence of the data, we included all $L R \mathrm{~s}$ with measured variances in the regression, except one study that was omitted owing to a high sample variance that disproportionately influenced the ICCs and regression.

We further tested the effect of absolute temperature difference (between study conditions and thermal optima) on impacts using a quantile regression of the upper 25 th percentile of all data points, including 16 IAS from 29 studies. This analysis assessed how temperature difference constrained the maximum impact potential, rather than the mean impact, which may be influenced by many abiotic and biotic variables (see Discussion). All analyses were conducted in $\mathrm{R}$ ( $\mathrm{R}$ Development Core Team 2012).

\section{Functional response experiments: data collection}

Predatory FRs of $H$. anomala and $M$. diluviana were measured on cultured Daphnia pulex, as daphniid cladocerans are preferred prey for both mysids (Bowers and Vanderploeg 1982, Borcherding et al. 2006). $H$. anomala was collected from the Port of Montreal, St.

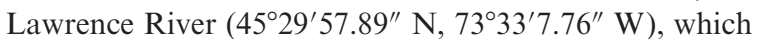
is within its invaded range; $M$. diluviana was collected from its native habitat in Lake Ontario $\left(3^{\circ} 42^{\prime} 58^{\prime \prime} \mathrm{N}\right.$, $78^{\circ} 1^{\prime} 40^{\prime \prime} \mathrm{W}$ and $\left.43^{\circ} 33^{\prime} 6^{\prime \prime} \mathrm{N}, 78^{\circ} 40^{\prime} 41^{\prime \prime} \mathrm{W}\right)$. After collection in October 2011, both mysids were maintained for a minimum of one week at $5^{\circ} \mathrm{C}$ in dechlorinated tap water and fed freeze-dried invertebrates (fish flakes) prior to use in experiments. Experimental temperatures were selected to span reported tolerance and preference ranges (Ricciardi et al. 2012): $H$. anomala was tested at $5^{\circ}, 10^{\circ}, 15^{\circ}, 20^{\circ}, 24^{\circ}$, and $28^{\circ} \mathrm{C}$, and $M$. diluviana was tested at $5^{\circ}, 10^{\circ}$, and $15^{\circ} \mathrm{C}$. H. anomala tolerates up to $28^{\circ} \mathrm{C}$ (Ioffe et al. 1968, Sun et al. 2013), whereas survival of $M$. diluviana declines rapidly at and above $15^{\circ} \mathrm{C}$ (Degraeve and Reynolds 1975, Johannsson et al. 2008). Temperatures were also originally chosen to provide a comparison between $H$. anomala and $M$. diluviana while extending the temperatures for $H$. anomala due to its higher temperature tolerance. However, the large differential in size of the species prevented a meaningful comparison, so here we focused on determining if, for each species, there was a match between optimal temperatures for maximum feeding rates and growth rates.

Mysids were starved for $24 \mathrm{~h}$ at experimental temperatures before being placed individually into containers with $170 \mathrm{~mL}$ of dechlorinated tap water and a known number of prey, which were placed in the containers $2-4 \mathrm{~h}$ prior to the experiments at densities of $4,6,8,10,16,20,30,40$, and 80 individuals, following the methods of Dick et al. (2013). Controls with prey at the highest density and in the absence of a predatory mysid were run simultaneously to ensure prey survival rates of at least $95 \%$. Thus, the highest density used at temperatures of $\geq 15^{\circ} \mathrm{C}$ was $40 \mathrm{D}$. pulex $/ 170 \mathrm{~mL}$, as higher densities caused reduced survival rates of prey in the controls. Experiments were run in the dark for $12 \mathrm{~h}$, after which the mysids were removed and preserved in ethanol and surviving D. pulex were counted. Trials were repeated when mysids molted during the experiment ( 8 trials out of 228 total), when mysids did not consume any prey as they were assumed to be stressed (often further indicated by listless movement; 9 trials), or when mysids died during the experiment (11 trials at the highest temperatures and 4 trials at an intermediate temperature). All prey densities were replicated to obtain 3 trials. Preserved mysids were measured to the nearest millimeter from the tip of the rostrum to the end of the telson with digital calipers, and their individual wet weights were measured after placing them on paper towel for approximately 1 minute to remove excess ethanol; $H$. anomala used in the experiment were visually size matched and had a body length of $7.0 \pm 0.6 \mathrm{~mm}$ (mean $\pm \mathrm{SD}$ ) and wet mass of $0.8 \pm 0.3 \mathrm{mg}$, whereas $M$. diluviana had a body length of $16.6 \pm 2.2 \mathrm{~mm}$ and wet mass of $5.6 \pm 2.1 \mathrm{mg}$.

Our FR experiments allowed for prey depletion. The prey depletion method has been found to provide similar maximum feeding rates as prey replacement designs (Alexander et al. 2012), though this method may be less adequate for comparing attack rates, the ability of the predator to search for and capture its prey as indicated by the initial slope of the curve (Dick et al. 2014). We followed the prey depletion design, given the difficulty in assessing depletion of $D$. pulex during the experiment and our focus on maximum feeding rates as the physiologically constrained parameter of the FR (Jeschke et al. 2002, Englund et al. 2011).

\section{Functional response experiments: data analysis}

We determined for each temperature and species whether the FR was of Type II or Type III, following the methods of Alexander et al. (2012) and Dick et al. (2013). We derived FR types using logistic regressions of the proportion of prey consumed as a function of prey density, and then modeled Type II curves with Rogers' 


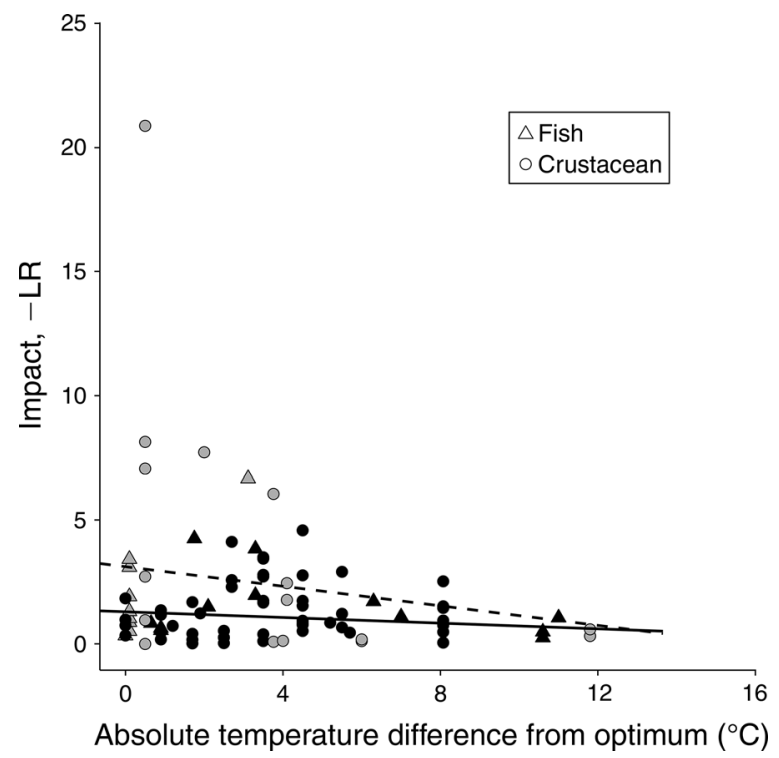

FIG. 1. Ecological impacts (negative log response ratios; LR) of invasive alien species decline significantly with an increasing absolute difference between their thermal optima and ambient study temperatures (temp. diff.). Consumptive impacts of invasive fishes (triangles) and crustaceans (circles) on native populations were fit with (1) a weighted linear regression (solid line, black symbols; fixed-effects model, $-\mathrm{LR}=1.29-$ 0.06[temp. diff.]; $P<0.0001$ ), excluding impacts for which sample variance could not be measured (gray symbols), and (2) a quantile regression of the upper 25th percentile of all data points (dashed line; $-\mathrm{LR}=3.11-0.20$ [temp. diff.]; $P=0.034$ ).

random predator equation (Rogers 1972) for nonreplacement of prey (Juliano 2001). Bootstrapping was subsequently used to generate multiple estimates $(n=15)$ of the handling time response parameter (Alexander et al. 2012). Maximum feeding rates were calculated as $1 /$ (handling time $\times$ experimental time) and were $\log _{10^{-}}$ transformed to improve normality (Shapiro-Wilk test, $P$ $>0.05$ ) and homogeneity of variances (Fligner-Killeen test, $P>0.05$ ). One-way analyses of variances were used to test the effect of temperature on maximum feeding rates separately for each mysid species, and Tukey's honest significant differences were used in post hoc comparisons of maximum feeding rates among temperatures. All analyses were conducted in R (R Development Core Team 2012).

\section{RESULTS}

Our meta-analysis revealed that the ecological impacts of IAS declined significantly as habitat temperatures shifted away from optimal conditions (fixed-effects model, heterogeneity explained by the model, $\mathrm{QM}=$ 87.24, $Z=-9.34, P<0.0001, n=62$; Fig. 1$)$. The residual heterogeneity estimator showed a significant level of between-study variance $(\mathrm{QE}=3221.10, P<$ 0.0001 ), indicating additional factors that influence impact (see Discussion). The quantile regressilon showed a stronger inverse relationship between the upper 25th percentile of measured impacts and difference between ambient and optimal temperatures $(t=$ $-2.15, P=0.034)$, with a steeper slope $(-0.20)$ than that of the meta-analysis regression $(-0.06)$.

Data were collected for 16 IAS, including seven fishes and nine crustaceans, from 29 studies (Appendix: Table A1). An attempt was made to include molluscs in the meta-analysis, but there were insufficient impact studies that reported ambient temperatures and that could be linked to thermal growth optima; therefore the final analysis included only fishes and crustaceans. The seven fish IAS included in the meta-analysis consisted of three salmoniformes, two cypriniformes, a perciforme, and a cyprinodontiforme. These included three omnivorous and four carnivorous species; the impacts recorded for the common carp Cyprinus carpio and the goldfish Carassius auratus were herbivorous, whereas all other fish impacts were predatory. The nine crustaceans in the meta-analysis comprised five decapods (two crabs, three crayfishes), two mysids, and two cladocerans. These comprised six omnivores and three carnivores; both herbivorous and predatory impacts were recorded for the Chinese mitten crab Eriocheir sinensis, the red swamp crayfish Procamabarus clarkii, and the rusty crayfish Pacifastacus leniusculus, while all other crustacean impacts were exclusively predatory. The round goby Neogobius melanostomus and the cladocerans (Limnomysis benedeni and Cercopagis pengoi) were native to the Ponto-Caspian region, three fishes and four crustaceans originated from North America, and the remaining fish and crustacean species were from Europe or Asia.

Logistic regression analysis on the FR data (proportion consumed vs. prey density) returned significantly negative linear coefficients $(P<0.01)$ and thus indicated that FRs of both species at all temperatures conformed to Type II curves (Fig. 2). Temperature had a significant effect on maximum feeding rates of both $H$. anomala $\left(F_{1,88}=10.28, P=0.002\right)$ and $M$. diluviana $\left(F_{1,43}=10.55\right.$, $P=0.002) . H$. anomala had the highest maximum feeding rate at $24^{\circ} \mathrm{C}$ and the lowest feeding rates at $5^{\circ}$, $15^{\circ}$, and $28^{\circ} \mathrm{C}$ (Fig. 3a). M. diluviana had a higher maximum feeding rate at $10^{\circ} \mathrm{C}$, an intermediate feeding rate at $5^{\circ} \mathrm{C}$, and a lower feeding rate at $15^{\circ} \mathrm{C}$ (Fig. 3b).

\section{DisCusSION}

\section{Temperature as a mediator of impact}

Our results support the hypothesis that ecological impacts of IAS are higher at habitat temperatures that most closely match their thermal optima. While climate change has been predicted to influence the ecological impacts of IAS on native communities (Hellmann et al. 2008, Rahel and Olden 2008), little is yet known about the relationship between temperature conditions and IAS impact levels. Higher temperatures could increase impacts of IAS up to a thermal optimum by raising metabolism (Huey and Stevenson 1979, Jobling 1981), thus mediating mechanisms of ectotherm consumption, 

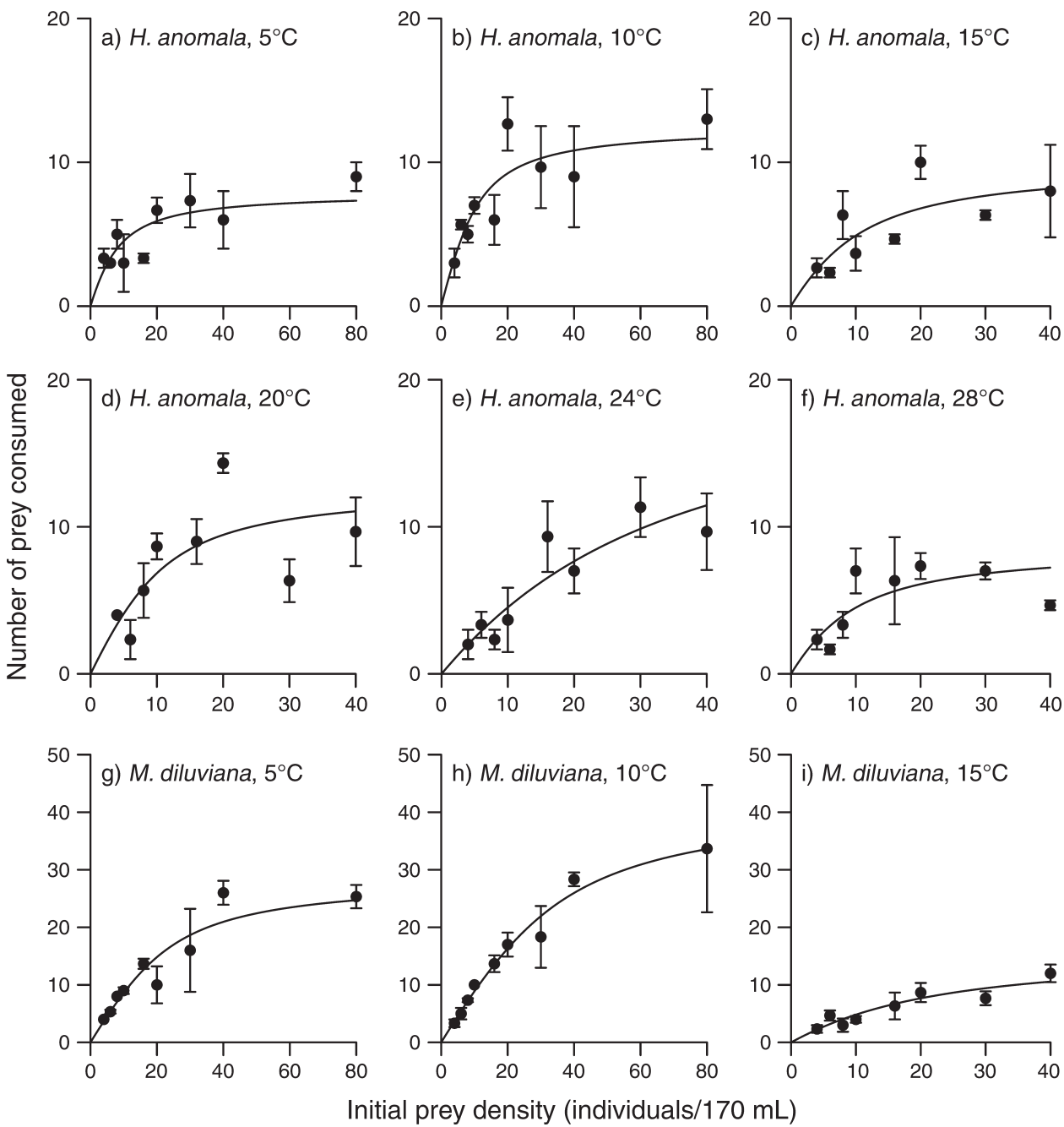

FIG. 2. Functional responses of (a-f) Hemimysis anomala from $5-28^{\circ} \mathrm{C}$ and (g-i) Mysis diluviana from $5-15^{\circ} \mathrm{C}$ on Daphnia pulex prey. Type II curves were fitted with Rogers' predator equation for decreasing prey densities. Error bars are \pm SE.

as defined by FRs (Englund et al. 2011). The impacts of IAS may be affected by a suite of other environmental factors (e.g., prey experience, habitat complexity, water chemistry), and a few previous studies provide support for the Environmental Matching Hypothesis by relating the impact of IAS to their adapted conditions, though not specifically to physiologically optimal conditions (Table 1). Identifying key habitat conditions that affect impacts of IAS, as well as the optimal range for maximum potential per capita effects and abundances, will enable predictions of which communities are most at-risk of disruption by established IAS. FRs combined with proxies of abundance, such as numerical response and growth rate, provide accessible tools that are necessary for such predictions.

Of the principal determinants of IAS impact (i.e., per capita effect, abundance, and range size; Parker et al. 1999, Yokomizo et al. 2009, Thomsen et al. 2011), per capita effect has heretofore been much more difficult to assess and has largely been quantified using correlations such as native abundances pre- and post-invasion (Parker et al. 1999). Our meta-analysis considers consumptive impacts of IAS influenced by both their per capita effects and abundances, as measured from correlative, per capita, and per biomass studies. However, per capita effect provides a more mechanistic understanding of impact and is important for detecting trait-based differences between invaders (Parker et al. 1999, Dick et al. 2014). FRs measured along temperature gradients supported our meta-analytical finding that IAS per capita effects are maximal where ambient and optimal temperature differences are minimal, and mechanistically relate this finding to physiologically determined maximum feeding rates. FRs revealed that the highest per capita impacts of $H$. anomala and $M$. diluviana on $D$. pulex were within $2^{\circ} \mathrm{C}$ of their published thermal growth optima: $20-22^{\circ} \mathrm{C}$ (Ioffe et al. 1968) and $8-8.5^{\circ} \mathrm{C}$ (Berrill and Lasenby 1983, Johannsson et al. 


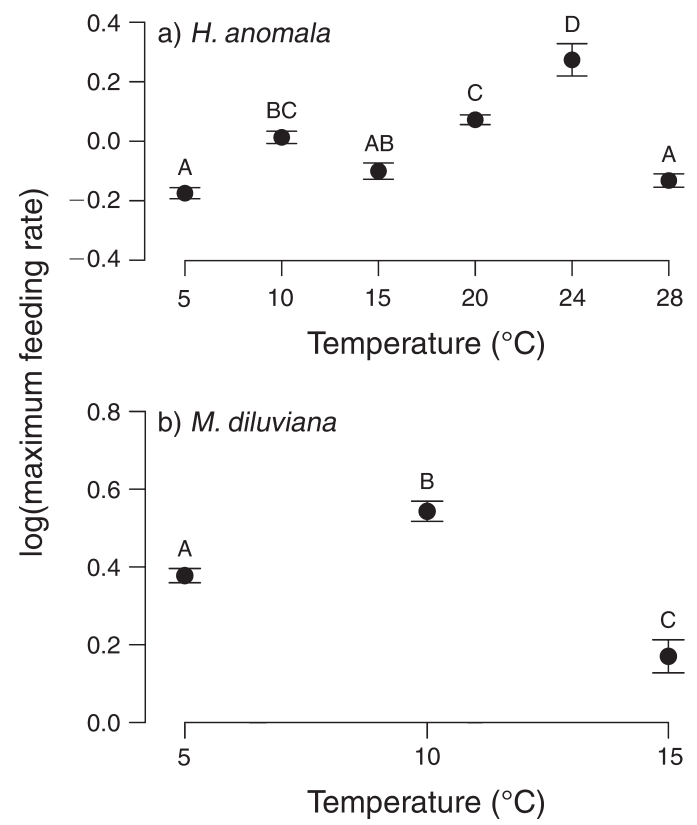

FIG. 3. Maximum feeding rates (no. Daphnia pulex consumed $/ \mathrm{h}$ ) of (a) Hemimysis anomala and (b) Mysis diluviana along temperature gradients. Type II functional response curves were bootstrapped for 15 replicates of maximum feeding rates. Error bars are $\pm \mathrm{SE}$, and data points that share a letter are not significantly different $(P<0.05)$.

2008), respectively. Measurements of $H$. anomala growth rates at temperatures higher than $20-22^{\circ} \mathrm{C}$ are not available to our knowledge; however, $H$. anomala has a unimodal temperature preference with the apex at 20- $22^{\circ} \mathrm{C}$ (Ioffe et al. 1968, Sun et al. 2013). Berrill and Lasenby (1983) found higher growth rates of $M$. diluviana at $8^{\circ} \mathrm{C}$ compared to $4^{\circ} \mathrm{C}$, and Johannsson and colleagues (2008) found the minimum duration of intermolt periods at $8.5^{\circ} \mathrm{C}$, and loss of respiratory stability and $50 \%$ death rates at $12.7^{\circ} \mathrm{C}$.

In our experiments, maximum feeding rates did not exhibit the distinct modal relationship with temperature that was found in the meta-analysis by Englund and colleagues (2011), but did indicate a peak in performance and lower maximum feeding rates at surrounding temperatures. Juvenile $H$. anomala were previously found to have increasing feeding rates on Bosmina up to $27^{\circ} \mathrm{C}$, after which mortality was too high to measure consumption (Sun et al. 2013). However, the Bosmina density used by Sun and colleagues (2013) was similar to our density of 10 prey, which, the FRs indicate, is a level at which predation by $H$. anomala is controlled more by attack rates (the ability to locate and capture prey, signified by the initial slope of the curve) than by physiologically dependent maximum feeding rates (Jeschke et al. 2002, Englund et al. 2011). M. diluviana had a similar response to temperature as found in other studies, in which they exhibit their highest feeding rates at $10-12^{\circ} \mathrm{C}$ (Chipps 1998 , Rudstam et al. 1999). Folt et al. (1982) measured the FR of $M$. diluviana on a preferred copepod prey and found a maximum feeding rate of approximately $3.4 \mathrm{prey} / \mathrm{h}$ at $8-10^{\circ} \mathrm{C}$, which was very similar to our measured maximum feeding rate of $3.6 \mathrm{prey} / \mathrm{h}$ at $10^{\circ} \mathrm{C}$. Where introduced, H. anomala and Mysis spp. strongly impact native species (Ketelaars et al. 1999, Ricciardi et al. 2012, Dick et al. 2013) and can even restructure entire food webs (Spencer et al. 1991,

TABLE 1. Studies indicating invasive alien species have higher impacts in environmental conditions for which they are evolutionarily adapted provide support for the Environmental Matching Hypothesis.

\begin{tabular}{|c|c|c|}
\hline $\begin{array}{l}\text { Impact measurement, environmental } \\
\text { gradient, and species }\end{array}$ & Relation to Environmental Matching Hypothesis & Reference \\
\hline \multicolumn{3}{|l|}{ Interspecific predation } \\
\hline Conductivity & $\begin{array}{l}\text { invader is dominant closest to its adapted } \\
\text { conditions }\end{array}$ & \\
\hline Echinogammarus ischnus & & Kestrup and Ricciardi (2009) \\
\hline Gammarus pulex and G. tigrinus & & Dick and Platvoet (1996) \\
\hline Oxygen concentration & $\begin{array}{l}\text { invader is more dominant at concentrations that it } \\
\text { tolerates better than the native }\end{array}$ & \\
\hline G. pulex & & MacNeil et al. (2004) \\
\hline $\begin{array}{l}\text { Aggressive behavior and food } \\
\text { competition }\end{array}$ & $\begin{array}{l}\text { invader is more aggressive and voracious closest to } \\
\text { its adapted conditions }\end{array}$ & \\
\hline \multicolumn{3}{|l|}{ Salinity } \\
\hline Gambusia holbrooki & & Alcaraz et al. (2008) \\
\hline \multicolumn{3}{|l|}{ Temperature } \\
\hline G. holbrooki & & $\begin{array}{l}\text { Rincon et al. (2002), } \\
\quad \text { Carmona-Catot et al. (2013) }\end{array}$ \\
\hline G. affinis & & $\begin{array}{l}\text { Rowe et al. (2007), Priddis et } \\
\text { al. (2009) }\end{array}$ \\
\hline Competitive exclusion & $\begin{array}{l}\text { invader is dominant closest to its adapted } \\
\text { conditions }\end{array}$ & \\
\hline \multicolumn{3}{|l|}{ Hydrology (drying) } \\
\hline Aedes albopictus & & Costanzo et al. (2005) \\
\hline
\end{tabular}


Ellis et al. 2011). The combination of FRs and growth optima suggest that habitats characterized by temperatures of $20-24^{\circ} \mathrm{C}$ and $8-10^{\circ} \mathrm{C}$ may be most vulnerable to high impacts from $H$. anomala and $M$. diluviana, respectively. The FRs and growth optima account for potential per capita effects and abundances in response to temperature conditions, whereas estimations of abundance in terms of numerical response might increase the accuracy of these predictions.

Both the meta-analysis and FRs suggested that the highest impact levels occurred in conditions a few degrees removed from optimal temperatures. Temperatures associated with maximal feeding rates for fishes are higher than measurements of thermal optima for growth (Jobling 1994). However, LRs in the meta-analysis were not positively skewed (higher when habitat temperature $>$ growth optima) in plotted plus-or-minus temperature differences, contrary to what would be expected if thermal optima for feeding are higher than for growth. Optimum temperatures for growth measured in laboratory settings of ad libitum feeding may be overestimates of optima under natural field conditions where feeding may be more limited (Elliott 1982). The weighted linear regression of data with measured variances supported the finding that impacts are higher when habitat temperatures are closer to optimal, while the upper quantile regression analysis clearly indicated that maximal impacts were more constrained by temperature differences.

\section{Implications for risk assessment}

Our results suggest that variation in the magnitude of impacts can be explained, in part, from thermal optima and that it is more feasible to predict maximum (or relative) impact potential, rather than actual impact values. Therefore, efforts to reduce IAS populations or prevent their spread may be most beneficial in areas that meet the optimal growth requirements of the invader, as defined by temperature and other physicochemical conditions. Between-study variation in the meta-analysis of IAS impact levels suggests the effects of additional abiotic and biotic factors on impact (Ricciardi et al. 2013). For example, water chemistry can affect consumption by increasing metabolic energy demands due to osmoregulation (Boeuf and Payan 2001); indeed, conductivity levels have been shown to mediate impacts by invasive Ponto-Caspian species, which evolved in ionrich waters (Jokela and Ricciardi 2008, Kestrup and Ricciardi 2009). Prey naiveté and the functional distinctiveness of the invader can also influence the impact of IAS (Ricciardi and Atkinson 2004, Sih et al. 2010). However, temperature is a particularly important factor as it has direct effects on all biological processes of ectotherms, at scales from molecular to behavioral (Pörtner et al. 2006). It is also a more accessible predictor of impact, as thermal optima and habitat temperatures are relatively easy to measure and more commonly reported in the literature. Impact predictions based on an environmental match between habitat conditions and physiological optima of IAS may be developed as a risk assessment tool similar to climatematching tools that are used for predicting establishment of IAS (e.g., Bomford et al. 2010, Britton et al. 2010). Climate change will be an important consideration when prioritizing at-risk habitats, as shifts in temperature may increase or decrease the impact of an invader depending on the proximity to its thermal optima.

As with niche-based models for establishment, differences in physiological responses between populations from native and invaded ranges may confound predictions of impact. Our meta-analysis incorporated growth optima measured from either the native or invaded range of IAS, based on availability of peer-reviewed studies, potentially increasing variability in the relationship between thermal optima and impact. There is growing evidence of rapid evolution of IAS leading to divergence both from the native population (Losos et al. 1997, Yonekura et al. 2007) and within invasive populations (Huey et al. 2000, Sexton et al. 2002, Maron et al. 2004). A few niche-based models have also shown IAS occurring outside of the predicted range based on their native habitat, though it is unknown whether this reflects a change in the realized or fundamental niche of the species (Broennimann et al. 2007, Loo et al. 2007, da Mata et al. 2010). Predicting impact based on the degree of concordance between habitat conditions and physiological optima may be most accurate when optima are measured from the same population of concern, though our meta-analysis shows a significant relationship between the two regardless of potential local adaptations. Thus, optima measured from different populations may be similar enough to provide baseline predictions necessary for timely management decisions.

Finally, our study further illustrates the utility of per capita measures such as functional responses to provide potentially valuable predictive information on the ecological impacts of IAS (Dick et al. 2014). Maximum feeding rates provide a direct measurement of per capita effects that successfully predict relative differences in IAS impacts in the field (Dick et al. 2013, 2014). When combined with other impact measures (principally, abundance and area occupied; Parker et al. 1999), this methodology could increase the predictive power of risk assessment. Further progress toward this goal may be gained by explicit consideration of the context-dependency of per capita impacts (Ricciardi et al. 2013), as illustrated here for temperature gradients.

\section{ACKNOWLEDGMENTS}

We thank Kelly Bowen and Sunci Avlijas for assistance with the functional response experiments. This research was funded by the Canadian Aquatic Invasive Species Network and by a Discovery grant from the Natural Sciences and Engineering Research Council of Canada to A. Ricciardi. Additional support was provided by the Group for Interuniversity 
Research in Limnology and Aquatic Environment (to J. C. Iacarella), the Leverhulme Trust and Natural Environment Research Council (UK) (to J. T. A. Dick), and Stellenbosch University's Centre for Invasion Biology (to M. E. Alexander).

\section{Literature Cited}

Alcaraz, C., A. Bisazza, and E. Garcia-Berthou. 2008. Salinity mediates the competitive interactions between invasive mosquitofish and an endangered fish. Oecologia 155:205-213.

Alexander, M. E., J. T. A. Dick, N. E. O'Connor, N. R. Haddaway, and K. D. Farnsworth. 2012. Functional responses of the intertidal amphipod Echinogammarus marinus: effects of prey supply, model selection and habitat complexity. Marine Ecology Progress Series 468:191-202.

Alexander, M. E., J. T. A. Dick, O. L. F. Weyl, T. B. Robinson, and D. M. Richardson. 2014. Existing and emerging high impact invasive species are characterized by higher functional responses than natives. Biology Letters 10:20130946.

Anger, K. 1991. Effects of temperature and salinity on the larval development of the Chinese mitten crab Eriocheir sinensis (Decapoda, Grapsidae). Marine Ecology Progress Series 72:103-110.

Beeton, A. M., and J. A. Bowers. 1982. Vertical migration of Mysis relicta Lovén. Hydrobiologia 93:53-61.

Berrill, M., and D. C. Lasenby. 1983. Life cycles of the freshwater Mysid shrimp Mysis relicta reared at 2 temperatures. Transactions of the American Fisheries Society 112:551-553.

Boeuf, G., and P. Payan. 2001. How should salinity influence fish growth? Comparative Biochemistry and Physiology C 130:411-423.

Bollache, L., J. T. A. Dick, K. D. Farnsworth, and W. I. Montgomery. 2008. Comparison of the functional responses of invasive and native amphipods. Biology Letters 4:166-169.

Bomford, M., S. C. Barry, and E. Lawrence. 2010. Predicting establishment success for introduced freshwater fishes: a role for climate matching. Biological Invasions 12:2559-2571.

Borcherding, J., S. Murawski, and H. Arndt. 2006. Population ecology, vertical migration and feeding of the Ponto-Caspian invader Hemimysis anomala in a gravel-pit lake connected to the River Rhine. Freshwater Biology 51:2376-2387.

Borenstein, M., L. V. Hedges, J. P. T. Higgins, and H. R. Rothstein. 2009. Introduction to meta-analysis. John Wiley and Sons, Chichester, UK.

Bowers, J. A., and H. A. Vanderploeg. 1982. In situ predatory behavior of Mysis relicta in Lake Michigan. Hydrobiologia 93:121-131.

Britton, J. R., J. Cucherousset, G. D. Davies, M. J. Godard, and G. H. Copp. 2010. Non-native fishes and climate change: predicting species responses to warming temperatures in a temperate region. Freshwater Biology 55:1130-1141.

Broennimann, O., U. A. Treier, H. Muller-Scharer, W. Thuiller, A. T. Peterson, and A. Guisan. 2007. Evidence of climatic niche shift during biological invasion. Ecology Letters 10:701-709.

Carmona-Catot, G., K. Magellan, and E. Garcia-Berthou. 2013. Temperature-specific competition between invasive mosquitofish and an endangered Cyprinodontid fish. PLoS ONE 8:e54734.

Charlebois, P. M., J. E. Marsden, R. G. Goettel, R. K. Wolfe, D. J. Jude, and S. Rudnicka. 1997. The round goby, Neogobius melanostomus (Pallus), a review of European and North American literature. INHS Special Publication No. 20. Illinois-Indiana Sea Grant Program, Urbana, Illinois, USA and Illinois Natural History Survey, Champaign, Illinois, USA.

Chipps, S. R. 1998. Temperature-dependent consumption and gut-residence time in the opossum shrimp Mysis relicta. Journal of Plankton Research 20:2401-2411.

Chipps, S. R., and D. H. Bennett. 2002. Evaluation of a Mysis bioenergetics model. Journal of Plankton Research 24:77-82.
Clutter, R. I., and G. H. Theilacker. 1971. Ecological efficiency of a pelagic mysid shrimp- estimates from growth, energy budget, and mortality studies. United States Fish and Wildlife Service Fishery Bulletin 69:93-115.

Costanzo, K. S., B. Kesavaraju, and S. A. Juliano. 2005. Condition-specific competition in container mosquitoes: the role of noncompeting life-history stages. Ecology 86:32893295.

da Mata, R. A., R. Tidon, L. G. Cortes, P. De Marco, and J. A. F. Diniz. 2010. Invasive and flexible: niche shift in the drosophilid Zaprionus indianus (Insecta, Diptera). Biological Invasions 12:1231-1241.

Degraeve, G. M., and J. B. Reynolds. 1975. Feeding behavior and temperature and light tolerance of Mysis relicta in the laboratory. Transactions of the American Fisheries Society 104:394-397.

Dick, J. T. A., et al. 2014. Advancing impact prediction and hypothesis testing in invasion ecology using a comparative functional response approach. Biological Invasions 16:735753.

Dick, J. T. A., et al. 2013. Ecological impacts of an invasive predator explained and predicted by comparative functional responses. Biological Invasions 15:837-846.

Dick, J. T. A., and D. Platvoet. 1996. Intraguild predation and species exclusions in amphipods: the interaction of behaviour, physiology and environment. Freshwater Biology 36:375-383.

Dunson, W. A., and J. Travis. 1991. The role of abiotic factors in community organization. American Naturalist 138:10671091.

Elliott, J. M. 1982. The effects of temperature and ration size on the growth and energetics of Salmonids in captivity. Comparative Biochemistry and Physiology B 73:81-91.

Ellis, B. K., J. A. Stanford, D. Goodman, C. P. Stafford, D. L. Gustafson, D. A. Beauchamp, D. W. Chess, J. A. Craft, M. A. Deleray, and B. S. Hansen. 2011. Long-term effects of a trophic cascade in a large lake ecosystem. Proceedings of the National Academy of Sciences USA 108:1070-1075.

Englund, G., G. Ohlund, C. L. Hein, and S. Diehl. 2011. Temperature dependence of the functional response. Ecology Letters 14:914-921.

Englund, G., O. Sarnelle, and S. D. Cooper. 1999. The importance of data-selection criteria: meta-analyses of stream predation experiments. Ecology 80:1132-1141.

Epifanio, C. E., A. I. Dittel, S. Park, S. Schwalm, and A. Fouts. 1998. Early life history of Hemigrapsus sanguineus, a nonindigenous crab in the Middle Atlantic Bight (USA). Marine Ecology Progress Series 170:231-238.

Folt, C. L., J. T. Rybock, and C. R. Goldman. 1982. The effect of prey composition and abundance on the predation rate and selectivity of Mysis relicta. Hydrobiologia 93:133-143.

Gorokhova, E. 1998. Exploring and modeling the growth dynamics of Mysis mixta. Ecological Modelling 110:45-54.

Gurevitch, J., and L. V. Hedges. 1999. Statistical issues in ecological meta-analyses. Ecology 80:1142-1149.

Haxton, T. J., and C. S. Findlay. 2008. Meta-analysis of the impacts of water management on aquatic communities. Canadian Journal of Fisheries and Aquatic Sciences 65:437-447.

Hedges, L. V., J. Gurevitch, and P. S. Curtis. 1999. The metaanalysis of response ratios in experimental ecology. Ecology 80:1150-1156.

Hedges, L. V., and I. Olkin. 1985. Statistical methods for metaanalysis. Academic Press, London, UK.

Hellmann, J. J., J. E. Byers, B. G. Bierwagen, and J. S. Dukes. 2008. Five potential consequences of climate change for invasive species. Conservation Biology 22:534-543.

Holling, C. S. 1959. Some characteristics of simple types of predation and parasitism. Canadian Entomologist 92:385398. 
Holling, C. S. 1966. The functional response of invertebrate predators to prey density. Memoirs of the Entomological Society of Canada 48:1-86.

Huey, R. B., G. W. Gilchrist, M. L. Carlson, D. Berrigan, and L. Serra. 2000. Rapid evolution of a geographic cline in size in an introduced fly. Science 287:308-309.

Huey, R. B., and R. D. Stevenson. 1979. Integrating thermal physiology and ecology of ectotherms - discussion of approaches. American Zoologist 19:357-366.

Ioffe, T. I., A. Salazkin, and V. V. Petrov. 1968. Biological basis for the enrichment of fish food resources in Gorkovsky, Kuibyshevsky and Volgogradsky reservoirs. Izvestiia Gosudarstvennogo Nauchno-issledovatelskogo Instituta Ozernogo in Rechnogo Rybnogo Khoziaistva 67:30-80.

Jeschke, J. M., M. Kopp, and R. Tollrian. 2002. Predator functional responses: discriminating between handling and digesting prey. Ecological Monographs 72:95-112.

Jobling, M. 1981. Temperature tolerance and the final preferendum - rapid methods for the assessment of optimum growth temperatures. Journal of Fish Biology 19:439-455.

Jobling, M. 1994. Fish bioenergetics. Chapman and Hall, London, UK.

Johannsson, O. E., K. L. Bowen, C. M. Wood, R. W. Smith, C. Chu, L. G. Rudstam, and B. Boscarino. 2008. Relating nucleic acid and protein indices to growth in Mysis relicta: ration, cycling temperature, and metabolism. Aquatic Biology 4:33-46.

Jokela, A., and A. Ricciardi. 2008. Predicting zebra mussel fouling on native mussels from physicochemical variables. Freshwater Biology 53:1845-1856.

Juliano, S. 2001. Nonlinear curve fitting. Design and analysis of ecological experiments. S. M. Scheiner and J. Gurevitch, editors. Chapman and Hall, New York, New York, USA.

Kestrup, A. M., and A. Ricciardi. 2009. Environmental heterogeneity limits the local dominance of an invasive freshwater crustacean. Biological Invasions 11:2095-2105.

Ketelaars, H. A. M., F. E. Lambregts-van de Clundert, C. J. Carpentier, A. J. Wagenvoort, and W. Hoogenboezem. 1999. Ecological effects of the mass occurrence of the PontoCaspian invader, Hemimysis anomala GO Sars, 1907 (Crustacea: Mysidacea), in a freshwater storage reservoir in the Netherlands, with notes on its autecology and new records. Hydrobiologia 394:233-248.

Lasenby, D. C., and R. R. Langford. 1972. Growth, life history, and respiration of Mysis relicta in an arctic and temperate lake. Journal of the Fisheries Research Board of Canada 29:1701-1708.

Loo, S. E., R. Mac Nally, and P. S. Lake. 2007. Forecasting New Zealand mudsnail invasion range: model comparisons using native and invaded ranges. Ecological Applications 17:181-189.

Losos, J. B., K. I. Warheit, and T. W. Schoener. 1997. Adaptive differentiation following experimental island colonization in Anolis lizards. Nature 387:70-73.

MacNeil, C., J. Prenter, M. Briffa, N. J. Fielding, J. T. A. Dick, G. E. Riddell, M. J. Hatcher, and A. M. Dunn. 2004. The replacement of a native freshwater amphipod by an invader: roles for environmental degradation and intraguild predation. Canadian Journal of Fisheries and Aquatic Sciences 61:1627-1635.

Maron, J. L., M. Vila, R. Bommarco, S. Elmendorf, and P. Beardsley. 2004. Rapid evolution of an invasive plant. Ecological Monographs 74:261-280.

Mills, M. D., R. B. Rader, and M. C. Belk. 2004. Complex interactions between native and invasive fish: the simultaneous effects of multiple negative interactions. Oecologia 141:713-721.

Osenberg, C. W., O. Sarnelle, and S. D. Cooper. 1997. Effect size in ecological experiments: the application of biological models in meta-analysis. American Naturalist 150:798-812.
Parker, I. M., et al. 1999. Impact: toward a framework for understanding the ecological effects of invaders. Biological Invasions 1:3-19.

Peterson, A. T. 2003. Predicting the geography of species' invasions via ecological niche modeling. Quarterly Review of Biology 78:419-433.

Pörtner, H. O., A. F. Bennett, F. Bozinovic, and A. Clarke. 2006. Trade-offs in thermal adaptation: the need for a molecular to ecological integration. Physiological and Biochemical Zoology 79:295-313.

Pörtner, H. O., and R. Knust. 2007. Climate change affects marine fishes through the oxygen limitation of thermal tolerance. Science 315:95-97.

Priddis, E., R. Rader, M. Belk, B. Schaalje, and S. Merkley. 2009. Can separation along the temperature niche axis promote coexistence between native and invasive species? Diversity and Distributions 15:682-691.

R Development Core Team. 2012. R: a language and environment for statistical computing. R Foundation for Statistical Computing, Vienna, Austria. www.r-project.org

Rahel, F. J., and J. D. Olden. 2008. Assessing the effects of climate change on aquatic invasive species. Conservation Biology 22:521-533.

Ricciardi, A., and S. K. Atkinson. 2004. Distinctiveness magnifies the impact of biological invaders in aquatic ecosystems. Ecology Letters 7:781-784.

Ricciardi, A., S. Avlijas, and J. Marty. 2012. Forecasting the ecological impacts of the Hemimysis anomala invasion in North America: lessons from other freshwater mysid introductions. Journal of Great Lakes Research 38:7-13.

Ricciardi, A., M. F. Hoopes, M. P. Marchetti, and J. L. Lockwood. 2013. Progress toward understanding the ecological impacts of nonnative species. Ecological Monographs 83:263-282.

Rincon, P. A., A. M. Correas, F. Morcillo, P. Risueno, and J. Lobon-Cervia. 2002. Interaction between the introduced eastern mosquitofish and two autochthonous Spanish toothcarps. Journal of Fish Biology 61:1560-1585.

Rogers, D. 1972. Random search and insect population models. Journal of Animal Ecology 41:369-383.

Rosenberg, M. S., D. C. Adams, and J. Gurevitch. 2000. MetaWin. Statistical software for meta-analysis. Sinauer Associates, Sunderland, Massachusetts, USA.

Rowe, D. K., J. P. Smith, and C. Baker. 2007. Agonistic interactions between Gambusia affinis and Galaxias maculatus: implications for whitebait fisheries in New Zealand rivers. Journal of Applied Ichthyology 23:668-674.

Rudnick, D., T. Veldhuizen, R. Tullis, C. Culver, K. Hieb, and B. Tsukimura. 2005. A life history model for the San Francisco Estuary population of the Chinese mitten crab, Eriocheir sinensis (Decapoda: Grapsoidea). Biological Invasions 7:333-350.

Rudstam, L. G. 1989. A bioenergetic model for Mysis growth and consumption applies to a Baltic population of Mysis mixta. Journal of Plankton Research 11:971-983.

Rudstam, L. G., A. L. Hetherington, and A. M. Mohammadian. 1999. Effect of temperature on feeding and survival of Mysis relicta. Journal of Great Lakes Research 25:363-371.

Sankurathri, C. S., and J. C. Holmes. 1976. Effects of thermal effluents on population dynamics of Physa gyrina Say (Mollusca: Gastropoda) at Lake Wabamun, Alberta. Canadian Journal of Zoology 54:582-590.

Sexton, J. P., J. K. McKay, and A. Sala. 2002. Plasticity and genetic diversity may allow saltcedar to invade cold climates in North America. Ecological Applications 12:1652-1660.

Sih, A., D. I. Bolnick, B. Luttbeg, J. L. Orrock, S. D. Peacor, L. M. Pintor, E. Preisser, J. S. Rehage, and J. R. Vonesh. 2010. Predator-prey naivete, antipredator behavior, and the ecology of predator invasions. Oikos 119:610-621.

Solomon, M. E. 1949. The natural control of animal populations. Journal of Animal Ecology 18:1-35. 
Spencer, C. N., B. R. McClelland, and J. A. Stanford. 1991 Shrimp stocking, salmon collapse, and eagle displacement. BioScience 41:14-21.

Sun, J., L. G. Rudstam, B. T. Boscarino, M. G. Walsh, and B. F. Lantry. 2013. Laboratory-derived temperature preference and effect on the feeding rate and survival of juvenile Hemimysis anomala. Journal of Great Lakes Research 39:630-636.

Taniguchi, Y., F. J. Rahel, D. C. Novinger, and K. G. Geron. 1998. Temperature mediation of competitive interactions among three fish species that replace each other along longitudinal stream gradients. Canadian Journal of Fisheries and Aquatic Sciences 55:1894-1901.

Thomsen, M. S., J. D. Olden, T. Wernberg, J. N. Griffin, and B. R. Silliman. 2011. A broad framework to organize and compare ecological invasion impacts. Environmental Research 111:899-908.

Tummers, B. 2006. DataThief III. http://datathief.org/

Viechtbauer, W. 2010. Conducting meta-analyses in R with the metafor package. Journal of Statistical Software 36:1-48.
Viola, D. V., E. A. Mordecai, A. G. Jaramillo, S. A. Sistla, L. K. Albertson, J. S. Gosnell, B. J. Cardinale, and J. M. Levine. 2010. Competition-defense tradeoffs and the maintenance of plant diversity. Proceedings of the National Academy of Sciences USA 107:17217-17222.

Walther, G. R., et al. 2009. Alien species in a warmer world: risks and opportunities. Trends in Ecology and Evolution 24:686-693.

Wolak, M. E., D. J. Fairbairn, and Y. R. Paulsen. 2012. Guidelines for estimating repeatability. Methods in Ecology and Evolution 3:129-137.

Yokomizo, H., H. P. Possingham, M. B. Thomas, and Y. M. Buckley. 2009. Managing the impact of invasive species: the value of knowing the density-impact curve. Ecological Applications 19:376-386.

Yonekura, R., K. Kawamura, and K. Uchii. 2007. A peculiar relationship between genetic diversity and adaptability in invasive exotic species: bluegill sunfish as a model species. Ecological Research 22:911-919.

\section{Supplemental Material}

\section{Ecological Archives}

An Appendix is available online: http://dx.doi.org/10.1890/14-0545.1.sm

\section{Data Availability}

Data associated with this paper have been deposited in the Dryad Digital Repository: http://dx.doi.org/10.5061/dryad.q8r53 